\title{
A HISTORIA ENSINADA NAS PROPOSTAS CURRICULARES (BRASIL - ÚLTIMAS DÉCADAS DO SÉCULO XX)
}

\section{Renilson Rosa Ribeiro}

"A história, como outras áreas do saber na área de Ciências Humanas, é muito sujeita aos ventos que sopram de latitudes as mais diferentes".

José Roberto do Amaral Lapa

Resumo: O presente ensaio tem o objetivo de analisar as representações do professor e da história ensinada nas propostas curriculares produzidas entre 1984 e 1995 no Brasil, dando especial ênfase às proposições da historiografia para as transformações no ensino da disciplina.

Palavras-Chave: História; Historiografia; Ensino; Currículo; Discurso

\begin{abstract}
This present essay has the purpose to analyse the teacher and History teaching representation in elaborated curriculum proposals between the years of 1984 and 1995 in Brazil, giving special emphasis to the historiography contribution for the discipline teaching changes.
\end{abstract}

Keywords: History; Historiography; Teaching; Curriculum; Discourse 


\section{O SABER HISTÓRICO NO DISCUR- SO CURRICULAR}

Os currículos constituem o instrumento mais significativo da intervenção do Estado no ensino, o que implica sua interferência, em última análise, na formação intelectual da clientela que freqüenta os bancos escolares para a prática da cidadania, no sentido que interessa aos que se encontram representados no poder (Abud, In: Bittencourt, 1998, p. 28).

Ao analisar os currículos escolares, devemos ter em mente que estes, no interior de seu texto, nos revelam um contexto social, econômico, cultural e político. Dessa forma, "despojando-o(s) do caráter neutro ligado a uma visão, que o(s) percebia $(m)$ como um mero veículo de transmissão desinteressada do conhecimento social" (Gasparello, In: Nikitiuk, 1999, p. 79).

Esse conhecimento, portanto, não pode apenas ser analisado como algo estático e naturalizado, como um conjunto de informações e materiais para ser absorvido por professores e alunos de maneira passiva.

Dessa maneira, uma análise do currículo não pode cair aos encantos de enxergar o processo de seleção e organização do conhecimento escolar como tão somente um "inocente" processo epistemológico em que intelectuais, acadêmicos, cientistas e educadores "desinteressados" e "imparciais" ditam, por ato de dedução lógica e filosófica, aquilo que melhor convém

\footnotetext{
${ }^{1}$ Este ensaio corresponde a uma versão modificada do segundo capítulo da Monografia de Bacharelado, intitulada Entre Textos \& Leituras: As representações do professor e da história ensinada no discurso histórico - últimas décadas do século $\mathrm{XX}$, defendida em dez. de 2001, sob a orientação do Prof. Dr. Paulo C. Miceli. Esta pesquisa foi financiada pelo PIBIC PRP/UNICAMP - CNPq (ago. 2001 - jan. 2002).
}

ser ensinado às crianças, jovens e adultos nas escolas e universidades.

Precisamos pensar que o currículo de História ou de qualquer outra disciplina tem seus autores; existem sujeitos por detrás deles que vão além da expressão "generalizante" e "homogenizadora" de Estado. Seria muito simples desenvolver uma análise usando a idéia de um poder central e único que determinasse as maneiras de agir e pensar dos indivíduos. Depois das proposições lançadas por Michel Foucault, tal "estratégia de análise" não se sustenta com tanta firmeza (1979).

O processo de criação do currículo não é um processo lógico, e sim um processo social, na qual convivem lado a lado com fatores lógicos, epistemológicos, intelectuais, determinantes sociais não tão "nobres" e "formais", tais como interesses, rituais, conflitos simbólicos e culturais, necessidades de legitimação e de controle, propósitos de dominação dirigidos por fatores ligados à classe, etnia, gênero conceitos construídos historicamente (Goodson, 1999, p. 17-28). Como afirmou Michel de Certeau, toda elaboração de uma pesquisa (e mesmo os currículos) "se articula com um lugar de produção sócio-econômico, político e cultural"'(2000, p. 66).

Além disso, necessitamos reconhecer que o próprio processo de construção social tampouco é internamente consistente, estático e lógico, consiste antes num amálgama de conhecimentos ditos "científicos", de crenças, de expectativas e de visões sociais.

Da mesma maneira, não se pode enxergar o currículo somente como resultado "síntese" - de uma construção no qual os diversos grupos se enfrentam num "campo de batalha" para fazer valer seus pontos de vista sobre o qual é o conheci- 
mento "correto" a ser oferecido às futuras gerações. Levando-se em consideração que a educação institucionalizada, de certa forma, representa uma espécie de condensação do social em cima da qual diferentes grupos refletem e projetam suas concepções de mundo e expectativas, o currículo acaba por expressar exatamente, entre outras coisas, a maneira como certas questões são definidas como "problemas" sociais ${ }^{2}$.

Dentro do texto curricular podemos identificar vários discursos presentes e ausentes, citados ou implícitos, que o constitui. Várias vozes, teorias, concepções, interesses, vontades constróem esse discurso (currículo). Podemos também buscar nesse texto as pistas que nos permitam encontrar os conhecimentos e saberes que foram deslocados ou rejeitados em favor de outros com mais prestígio, mais força e mais viabilidade social.

\section{Devemos ter em que}

"A luta para definir um currículo envolve prioridades sociopolíticas e discurso de ordem intelectual" (Goodson, 1999, p. 28).

Nesse discurso que se constrói, forma-se modelos de professores, de alunos, de escola, de sociedade, de política, de disciplinas, de condutas. Produz-se sujeitos dotados de identidades que lhes são atribuídas (classe, gênero, etnia, nacionalidade). Nessa perspectiva, o currículo produz identidades e subjetividades determinadas. Ele não apenas representa, ele cria, constrói sujeitos. As propostas de modificações de um currículo têm conexões muito estreitas com o tipo de sociedade

\footnotetext{
${ }^{2}$ Basta pensarmos nas várias propostas recentes para introduzir nos novos currículos questões tidas como problemas sociais para serem trabalhadas pelas disciplinas escolares no ensino fundamental e médio. Cf.: Parâmetros Curriculares Nacionais para o Ensino Fundamental, 1998)
}

que se pretende formar. Inclusões e exclusões no seu texto implica, na maioria das vezes, inclusões e exclusões na sociedade.

Nesse sentido, efetivamos um movimento de "dessacralização" do currículo, reconhecendo sua historicidade com suas implicações políticas, sociais e culturais e a presença de seus autores - aqueles que determinam o "melhor" a ser transmitido por professores aos alunos. Esses autores constróem discursos que estão vinculados aos lugares de produção e política cultural de onde esses falam.

No currículo são revelados e questionados elementos que anteriormente eram vistos como "naturais" e "sagrados", como, por exemplo, a sua estrutura disciplinar e seus conteúdos “oficiais"(Cf. Hobsbawm \& Ranger, 1984). Para Kátia Abud,

"através dos programas curriculares divulgam-se as concepções científicas de cada disciplina, o estado de desenvolvimento em que as ciências de referência se encontram e, ainda, que direção devem tomar ao se transformar em saber escolar. Nesse processo, o discurso do poder se pronuncia sobre a educação e define seu sentido, forma, finalidade e conteúdo e estabelece, sobre cada disciplina, o controle da informação a ser transmitida e da formação pretendida. Assim, a burocracia estatal legisla, regulamenta e controla o trabalho pedagógico"(In: Bittencourt, 1998, p. 28).

É importante acrescentar que o discurso presente no currículo não é apenas informação, mas envolve a produção ativa de sensibilidades, maneiras de percepção de "si" e dos "outros", formas particulares de agir, sentir, operar sobre "si" e o "mundo". Enfim, aprender informações no espaço da escola é também aprender uma determinada maneira, assim como maneiras de conhecer, compreender e interpre- 
tar o mundo em geral e seu "eu" nesse mundo (Stephanou, 1998, p. 18).

Entretanto, devemos ter em mente que há diferenças, clivagens e conflitos entre o "currículo pré-ativo" (prática idealizada), normativo e escrito pelos representantes do poder educacional instituído e o currículo como prática em sala de aula ou "currículo interativo":

"o que está prescrito não é necessariamente o que é apreendido, e o que se planeja não é necessariamente o que acontece (...) devemos procurar estudar a construção social do currículo tanto em nível de prescrição como em nível de interação" (Goodson, 1999, p. 78).

Esse aspecto apresentado por Ivor Goodson (1999) sobre teoria e prática remete-nos as proposições de De Certeau (1994) sobre o ato da leitura e da interpretação. Estes autores aproximam-se ao desconstruir idéia de uma leitura "objetiva" e "passiva" do texto (currículo) em defesa da subjetividade dessa prática. Em linhas gerais, nas suas análises, os professores e os alunos passam a ser reconhecidos na sua condição de "sujeitos" e não como meros "reprodutores" de prescrições atribuídas por aqueles que se encontram num nível superior de "intelectualidade" para determinar o que seria correto e errado para ser ensinado.

A leitura, para De Certeau, não é um ritual de passividade e renúncia do leitor perante o texto (o "sagrado"). Leitura seria a peregrinação por "um sistema imposto", seria uma "caçada" no território (texto) do outro (autor). Ao pensarmos uma análise do currículo ou qualquer outro texto, devemos levar em consideração "as manifestações de liberdade do leitor" (professor e aluno). Afinal, como nos lembrou o autor, "é sempre bom recordar que não se devem tomar os outros por idiotas"(De Certeau, 1994, p. 273).

Outro aspecto a ser levado em consideração da diferença entre o "currículo préativo" e o "currículo interativo" é que o primeiro trabalhou no universo do "ideal", do "imaginado", e não com a situação de universo complexo, repleto de diversidades, como a escola brasileira se constitui. Nesse sentido, Abud observou que os currículos

"não relativizam a realidade e trabalham com a ausência de rupturas e resistências. As dificuldades e obstáculos do cotidiano estão ausentes dos textos. Os currículos e programas das escolas públicas, sob qualquer forma que se apresentem (guias, propostas, parâmetros), são produzidos por órgãos oficiais. Que os deixam marcados com suas tintas, por mais que os documentos pretendam representar o conjunto dos professores $e$ $o$ 'interesse dos alunos'. E por mais que tais grupos reivindiquem participação na elaboração de instrumentos de trabalho, ela tem se restringido a leitura e discussões posteriores à sua elaboração"(Bittencourt, 1998, p. 29).

Mesmo com as possíveis críticas que possamos fazer aos currículos não podemos negligenciar ou marginalizar esses textos nas discussões sobre o ensino de História no Brasil, pois eles representam uma forma de produção do conhecimento que será acessível à maioria da população escolarizada no nível fundamental e médio.

\section{O ENSINO DE HISTÓRIA E A OFI- CINA HISTORIOGRÁFICA}

No contexto de Reforma Curricular, iniciado nos anos 1980, tem-se reforçado os diálogos entre pesquisadores e docentes do ensino de $1^{\circ}$ e $2^{\circ}$ graus, ao mesmo tempo em que se assistia a uma expansão dos cursos de pós-graduação em História, 
com a presença significativa de professores de $1^{\circ}$ e $2^{\circ}$ graus, cuja produção - especialmente as experiências e projetos didáticos alternativos inovadores no campo do ensino de História - foi absorvida parcialmente pela expansão editorial no campo da história ensinada e da historiografia (Cf. Lapa, 1985; Cordeiro, 1994; Freitas, 1998).

As propostas curriculares, que a partir de 1983 começaram a ser elaboradas e discutidas nas várias secretarias estaduais e municipais de educação, de forma muito diversa e heterogênea, passaram a ser influenciadas pelos debates entre as várias tendências historiográficas que surgiam nos meios acadêmicos Brasil desde os anos 1970. Segundo Luzia Margareth Rago, essa explosão

"de uma expressiva produção historiográfica brasileira ocorre, ainda, num momento em que se tornam visíveis os sinais de esgotamento do marxismo enquanto modelo privilegiado de interpretação do passado. Das primeiras análises marxistas que procuravam definir, inicialmente de maneira bastante mecanicista, posteriormente de modo mais sofisticado, as estruturas sócio-econômicas e os modos de produção existentes no país passou-se, nos anos setenta, a discutir o universo mental e as ideologias presentes nas análises históricas da "realidade brasileira”(Rago, s.d., p.2-3).

De maneira geral, essa produção acadêmica, que se desenvolveu no final dos anos 1970 e 1980, procurou acompanhar e atualizar-se com os desenvolvimentos teóricos, metodológicos e temáticos que se produziam para além de nossas fronteiras, em especial, na França, Inglaterra, Itália e nos Estados Unidos, locus de onde vêm nossas principais referências teóricas, metodológicas e temáticas. Entretanto, podemos identificar em tal produ- ção historiográfica brasileira a preocupação, como nos lembrou Rago,

"em trabalharem-se as especificidades locais das experiências históricas tal qual se constituem no país, nos diferentes estados, cidades e municípios e outras regiões, diferindo radicalmente daquelas vivenciadas em outros contextos históricos" (s.d., p.2).

Quanto à produção historiográfica brasileira durante a ditadura militar pós-1964, podemos encontrar uma análise elaborada por José Roberto do Amaral Lapa, em 1985. Para o referido autor, a produção científica dos historiadores brasileiros desse período não poderia ser deslocada das repercussões e influências do movimento político-militar de 1964.

Embora não rejeitasse as repercussões negativas das perseguições aos intelectuais realizadas pelo governo militar, Lapa (1985) observou que a produção ideológica do regime militar não conseguiu marcar o conhecimento histórico. Essa produção ideológica, de forma preferencial, orientou-se para os caminhos do ensino de $1^{\circ}$ e $2^{\circ}$ graus, com alguma interferência no ensino superior, inclusive criando para tanto novas disciplinas: Estudos Sociais, Educação Moral e Cívica, Organização Social e Política Brasileira, Estudo dos Problemas Brasileiros. Além disso, destaca o autor a relevância dos cursos da Escola Superior de Guerra como formuladora do discurso ideológico a ser absorvido pela sociedade.

Em análise sobre as linhas gerais desse discurso, Lapa afirmou que

"o entendimento e a dissecação do processo histórico brasileiro são realizados - em suas estratégias e projeções - através de antigas e superadas utilizações de teses como a do caráter nacional brasileiro, do homem cordial e quejandos" (1983, p. 26). 
Ao criar tais dispositivos de difusão ideológica, não parecia necessário ao regime militar interferir diretamente na produção do conhecimento histórico nas universidades, à não ser em casos de intelectuais e estudantes que se opusessem declaradamente ao governo estabelecido. Nesse sentido, o autor evidenciou que a violência sobre a universidade, com as cassações, aposentadorias compulsórias e perseguições, afetaram sobremaneira a produção em torno de alguns temas políticos e sociais mais diretamente visados pela repressão 3 .

Contudo, de acordo com Lapa, houve uma produção historiográfica significativa no período, principalmente nos anos 1970, e a tradução de diversas obras de historiadores importantes no plano internacional, que passavam despercebidas pela censura.

Data desse momento a entrada e difusão no Brasil de historiadores ingleses como Eric Jay Hobsbawm, E. P. Thompson, Christopher Hill, e/ou dos historiadores franceses da chamada Nova História, terceira geração dos Annales ${ }^{4}$, que passaram

\footnotetext{
${ }^{3} \mathrm{O}$ Ato Institucional de n. 5 (AI-5), de dezembro de 1968, foi significativo dentro desse processo de repressão e censura instaurado pela ditadura militar. Nesse momento, muitos intelectuais, políticos e estudantes opositores ao regime se viram forçados a abandonar o país devido à intensificação das perseguições violentas. Um relato emocionante sobre esse período pode ser encontrado no livro Pedagogia da Esperança: um reencontro com a Pedagogia do Oprimido (1993), do educador brasileiro Paulo Freire, exilado em 1968.

${ }^{4}$ A influência de outros historiadores dos Annales no Brasil data desde a fundação da Universidade de São Paulo, nos anos 1930. De acordo com Hebe Castro, "é marcante a influência da história econômica e social, à maneira dos 'Annales', nas abordagens adotadas pelos historiadores das décadas de 1950 e 1960, especialmente na Universidade de São Paulo" (In: Cardoso \& Vainfas, 1997, p. 55). A experiência do historiador Fernand Braudel na Seção de História da USP é analisada por Paulo C. Miceli no artigo "Sobre História,
}

a exercer grande influência nos meios especializados (Cf. Castro, In: Cardoso \& Vainfas, 1997).

Para Hebe Castro, o desenvolvimento da historiografia brasileira e a expansão e consolidação da profissionalização do historiador no país ao longo anos 1970 e, principalmente, 1980, é tributária também da expansão e consolidação dos cursos de pós-graduação, "que se faria, em grande parte, concomitantemente à crise dos referenciais teóricos até então predominantes"(1997, p. 55).

Além da expansão da pós-graduação no Brasil, Lapa (1985) valorizou ainda o crescimento quantitativo de cursos de graduação em História; a criação, no início dos anos 1960, da Associação Nacional dos Professores Universitários de História (ANPUH), com sua base inicial no núcleo paulista, e sua reestruturação no anos 1970 e 1980 com aceitação, não muito tranqüila, de professores de História do ensino de $1^{\circ}$ e $2^{\circ}$ graus e estudantes no seu quadro de associados, que levou a algumas cisões; o surgimento de novas revistas e, na área de divulgação, o aparecimento de coleções paradidáticas (como as coleções da Editora Brasiliense) que ofereceram espaços mais amplos para a produção dos historiadores brasileiros (Cf. Ricci, 1992).

Os historiadores brasileiros, nesse período, voltaram-se, influenciados pela Nova História francesa e pelos historiadores da moderna História Social inglesa, para a abordagem de novas problemáticas e temáticas de estudo, sensibilizados por

\footnotetext{
Braudel e os vaga-lumes, a Escola dos Annales e o Brasil (ou vice-versa)" (In: Freitas, 1998).

${ }^{5}$ Essa diversidade de temas e abordagens tem sido alimentada e fundamentada pelo diálogo da História com outras áreas de conhecimento das Ciências Humanas - a Filosofia, a Economia, a Política, a Sociologia, a
} 
questões ligadas à história social, cultural e do cotidiano, sugerindo possibilidades de rever no ensino de $1^{\circ}$ e $2^{\circ}$ graus o formalismo da abordagem histórica denominada de "tradicional"(Cordeiro, 1994, p. 121-62).

Margareth Rago, em sua análise sobre a historiografia brasileira nos anos 1980, enfatizou a importância das contribuições teóricas das obras de Walter Benjamin (1982), E. P. Thompson (1987), Cornelius Castoriadis (1986) e Michel Foucault (1984). A autora também destacou a renovação apresentada pela redescoberta dos Annales, obscurecida pela produção marxista desde o final dos anos 1960, e da Nova História, que encanta com seus novos temas, problemas e abordagens, sobretudo nos anos 1980 (Cf. Rago, 1995).

Com certeza, a leitura desses autores pode-nos oferecer significativas informações sobre o embasamento teórico e metodológico referente à produção do conhecimento histórico que influenciaram a construção de novos currículos para a disciplina a partir de então. Devemos ressaltar, por outro lado, a importância dos trabalhos historiográficos produzidos por autores brasileiros, influenciados por essas leituras e pelos acontecimentos internos, que trouxeram novas perspectivas para a História, tanto na academia, quanto no ensino de $1^{\circ}$ e $2^{\circ}$ graus. Muitos desses autores fizeram parte de equipes envolvidas com a elaboração e aplicação de novos currículos para a disciplina História no ensino de $1^{\mathrm{o}}$ e $2^{\circ}$ graus, na estruturação dos cursos de graduação e pós-graduação em História, e na formação de linhas e centro de pesquisa historiográfica no Bra-

Psicologia, a Antropologia, a Arqueologia, a Crítica Literária, a Lingüística e a Arte (Cf. Burke, 1992). sil, especialmente no eixo Rio-São Paulo, nos anos 1980 e 1990.

Walter Benjamin ao desenvolver uma crítica da memória histórica, tida como memória oficial e hegemônica, a qual condena ao "silêncio" os vencidos; E. P Thompson, ao lado de outros historiadores da História Social inglesa, críticos da produção marxista anterior, ao trazer não só um novo conceito de classes sociais, mas também toda uma ênfase nos aspectos culturais subjetivos antes deixados de lado; Cornelius Castoriadis ao criticar os limites do conceito de ideologia e propor o de "imaginário social" - esses autores trouxeram um novo fôlego para a escrita da história brasileira ao propor a volta do "sujeito" como centro das análises.

Tendo essas leituras como referência, os historiadores brasileiros passaram a analisar a condição operária no cotidiano da vida social das cidades, "dentro e fora dos muros das fábricas, percebendo os mecanismos de controle e disciplinarização dos trabalhadores, que se difundem nas primeiras décadas do século, num momento de intensa industrialização e urbanização". Alguns atentaram seus olhares para as tendências políticas que dominaram o movimento operário (anarquistas, socialistas, comunistas), destacando sua relevância para a formação da classe operária brasileira, outros buscaram os trabalhadores fora do campo da militância política, enfatizando as formas cotidianas da vida social, e ainda teve aqueles que partiram para o estudo do universo cultural, artístico e literário construídos pelos trabalhadores e militantes (anarquistas e anarcosindicalistas) nos primeiros tempos do século XX (Rago, s.d., p.5-6).

Outros sujeitos sociais, de maneira progressiva, foram incorporados nos estudos historiográficos dos anos 1980: "mulhe- 
res, negros, escravos, homossexuais, prisioneiros, loucos, crianças constituíram uma ampla gama de excluídos, que reclamaram seu lugar na História social do país" (Idem).

Michel Foucault ao afirmar, em seus estudos, "a positividade do poder, dos micropoderes que engendram individualidades, que produzem o real, classificam os corpos e normatizam os gestos; chamando a atenção para a materialidade do discurso e para a sua dimensão de estratégias discursivas práticas instituintes; atentando para os modos de subjetivação e para os jogos consigo mesmo", deslocou o sujeito, tão caro aos historiadores sociais, da centralidade que ocupava no pensamento ocidental e abala nossas estruturas. Essa análise irrompeu nos meios acadêmicos brasileiros, nesse período, como um "furacão", provocando, segundo Rago, "amores e ódios, fortes adesões e infinitas contestações, sobretudo dos que reclamam a luta das classes como motor da História" (Idem, p.7).

Apesar das contribuições significativas de Michel Foucault para a História, enquanto campo de pesquisa e de ensino, apenas alguns aspectos de suas proposições foram incorporados aos debates sobre a Reforma Curricular da disciplina no ensino de $1^{\circ}$ e $2^{\circ}$ graus durante a década de 1980 (e 1990). Rago ressaltou que, nesse

\footnotetext{
${ }^{6}$ Se observarmos as propostas curriculares, como a de São Paulo, apenas encontraremos referência, de forma superficial, à sua nova concepção de poder, apresentada no livro de ensaios, organizado por Roberto Machado, Microfísica do Poder (1979) - único texto citado do autor nas referências bibliográficas e no corpo do texto da proposta curricular de São Paulo de 1992. No caso dessa proposta, percebemos uma confusão dos autores que mesclaram as discussões de Foucault sobre a positividade do poder com a realidade das classes sociais e constituição dos sujeitos de influência da "História Social" (E. P. Thompson), sem prestar atenção às particularidades de cada postura analítica e suas divergências. Apesar de valorizar a diversidade da produção historiográfica, os autores da proposta tenderam a concentrar
}

momento, "E. P. Thompson estourava nas paradas de sucesso historiográfico, abrindo novas perspectivas para a "história social", traduzido e difundido por todo mundo" (1995, p. 69).

Todavia, devemos observar que as proposições da História Social inglesa, representada por E. P. Thompson, assim como Michel Foucault, e os historiadores brasileiros inspirados em suas teorias, sofreram rejeições dentro e fora da academia.

As contribuições da Nova História para a historiografia e o ensino de História, nesse contexto, vieram através da ampliação do "leque temático" (instintos, sentimentos, medo, amor, cheiro, lágrimas, clima, culinária entre outros) e da "noção de documento" Cf. Burke, 1991; Cordeiro, 1994).

A partir de então, evidenciamos o desenvolvimento de pesquisas no campo da história do cotidiano, da história vista de baixo, da micro-história, história oral, história das mulheres, história da leitura, história da criança entre outras (Cf. Burke, 1992).

No final dos anos 1980, com a intensificação dos estudos da obra de Foucault e a publicação da tradução dos livros de Roger Chartier, Michel de Certeau, Hayden White, Dominick La Capra entre outros, a determinação cultural dos agentes e das práticas sociais, para além da econômica e política, revelou-se na leitura que esses historiadores passaram a desenvolver sobre as subjetividades, o imaginário e o campo simbólico (Cf. Rago \& Gimenes, 2000). Vemos emergir, nesse momento, como uma reinterpretação e problematização da história das mentalidades dos

suas análises numa única perspectiva analítica (Cf. Proposta curricular para o ensino de História $-1^{\circ}$ grau, 1992, p. 12). 
Annales, a história cultural como outro campo de pesquisa dentro da História. Roger Chartier (1990), historiador vinculado, por origem e vocação, à historiografia francesa, sistematizou as inovações trazidas por uma postura historiográfica que assume sua ruptura com a crença no real e no social. Para além da construção cultural de nossas referências, o autor enfatizou o estudo das práticas de leitura e apropriação da cultura, destacando os movimentos complexos da circulação das idéias. Para Ronaldo Vainfas,

"É contra esta "tirania do social" que se insurge Chartier, defendendo, por outro lado, a necessidade de buscar-se o social em conexão com as diferentes utilizações do equipamento intelectual disponível (o outillage mental). Para dar conta de sua proposta, Chartier propõe um conceito de cultura enquanto prática, e sugere para o seu estudo as categorias de representação e apropriação" (In: Cardoso \& Vainfas, 1997, p. 154).

Com o diálogo e os debates realizados entre esses autores, suas posturas analíticas da cultura, e, principalmente, de seus leitores e críticos, nos anos 1990 podemos observar que a História Cultural confirma-se como uma linha teórica preocupada em apresentar e analisar os novos caminhos para a escrita da História no que concerne à linguagem e às relações "saber e poder". Essa postura teórica tem permitido reflexões sobre a produção do conhecimento histórico, a partir de áreas temáticas específicas:

"escrita da história, discurso, fato e narratividade, ciência e ficção, literatura e história, tempo e temporalidade são questões presentes nas discussões que abordam temas referentes tanto à teoria, quanto à política e à religiosidade"(Rago ; Gimenes, 2000, p. 1011).
Nesse sentido, trabalhos como de Roger Chartier ${ }^{7}$, sobre a história das práticas de leitura; de Michel de Certeau, analisando a construção do discurso historiográfico e a invenção do cotidiano; de Michel Foucault, Hayden White e Dominick LaCapra, referentes à linguagem e às relações entre o saber e o poder, têm oferecido significativas contribuições para a pesquisa historiográfica no Brasil e no mundo. Contudo, devemos ressaltar, como salientou muito bem Lynn A. Hunt (1992), que não há uma homogeneidade entre esses autores citados, cada um apresenta suas particularidades ao tratar da História Cultural. Assim, comprovando a pluralidade que caracteriza essa área da História.

Para Rago, depois dessas leituras, principalmente as contribuições de Foucault,

"não podemos mais falar em totalidade histórica, 'realidade objetiva', em determinações fundamentais de infra-estrutura econômica sobre tudo o mais desprevinidamente, nem podemos deixar de pensar diferentemente o documento. Nesse momento, nos damos conta de que o historiador trabalha primeiramente com a produção de discursos, com interpretações, com máscaras sobre máscaras e que a busca da objetividade de uma suposta essência natural é mais uma ilusão antropológica" (s.d., p.7-8).

Essas novas abordagens historiográficas presentes no universo dos historiadores brasileiros no final dos anos $1970 \mathrm{em}$

\footnotetext{
7 Algumas das proposições de Michel de Certeau e Roger Chartier podem ser identificadas nas propostas teórico-metodológicas dos Parâmetros Curriculares Nacionais - História. Aliás, é perceptível a tentativa de um diálogo entre as mais recentes posturas historiográficas no interior do documento dedicado à disciplina. Contudo, Marcos A. Silva observou que a fundamentação historiográfica do referido documento peca por sua superficialidade e falta de atenção às particularidades dos autores citados. A sua crítica recaiu, principalmente, no uso "deformado" das obras e conceitos chaves dos historiadores Fernand Braudel e E. P. Thompson (Cf. Silva, In: Lenskij \& Helfer, 2000, p.109-22).
} 
diante têm conduzido à diferentes contestações da chamada (rotulada) "história tradicional". Suas vertentes historiográficas de apoio (positivismo, estruturalismo, marxismo ortodoxo e historicismo), constituidoras de macrobjetos, estruturas ou modos de produção, nesse momento, foram colocadas sob suspeição. A apresentação do processo histórico como uma seriação de acontecimentos num eixo espaço-temporal europocêntrico, seguindo um processo evolutivo e seqüência de etapas que cumpriam uma trajetória histórica, foi acusada como redutora da capacidade do professor e do aluno, como sujeitos comuns, de sentir parte integrante e agente de uma história que desconsiderava sua vivência, e era apresentada como uma verdade, um produto pronto e acabado.

Introduziu-se, assim, a chamada "história crítica", com a pretensão de desenvolver com os alunos de $1^{\circ}$ e $2^{\circ}$ graus atitudes intelectuais de desmistificação das ideologias, permitindo a análise das manipulações dos meios de comunicação de massas e da sociedade de consumo (Cf. Ferro, 1983 e 1989).

A partir dessa abertura dada para se repensar o ensino de História, os professores e os pesquisadores começaram a questionar não somente os currículos, mas também a escola, os livros didáticos e os conteúdos estabelecidos de forma vertical pelas autoridades educacionais (Cf. Silva, 1984; Cabrini et al, 1984; Pinsky, 1994). Segundo Elza Nadai, esse "processo caminhou da impotência à desesperança e desta ao DESAFIO de se pensar o "novo"" (1986, p. 112).

Aos poucos foi se percebendo "aqui", "lá", "ali", "acolá" professores, ora em caráter individual ora em equipes que respondiam ao desafio posto pela escola, propondo alguma experiência "inovadora" ensaiando alguns projetos, muitas vezes nos Estados onde a oposição ao retorno da "democracia popular" saiu vitoriosa, como São Paulo, incentivados pelas próprias delegacias de ensino e secretarias de educação. Neste sentido,

"aqui recuperava-se o antigo, já acontecido, ali tentava-se algo novo. Seminários, Encontros e Congressos debatendo o desenrolar das experiências foram correndo, ganhando cada vez mais adeptos" (Idem).

Nesse contexto, envolvidos pelos debates sobre a reforma do currículo, pelas novas abordagens historiográficas e pelas novas experiências didáticas, os professores preocupados com a questão do ensino de História começaram a denunciar a inviabilidade de transmitir aos alunos o conhecimento de "toda" a história da humanidade em todos os tempos. Outros indagaram se deveriam iniciar o ensino pela História Geral ou pela História do Brasil - optando alguns pela alternativa de trabalhar com os alunos uma ordenação seqüencial e processual, a qual intercalasse os conteúdos num processo contínuo, desde a Antiguiidade aos dias atuais. Alguns professores optaram por começar os estudos pelo "olhar" dos povos americanos, partindo de uma crítica à visão histórica europocêntrica. Outros propuseram trabalhar com os alunos conteúdos ligados a uma história local e regional. Houve aqueles que criticaram um ensino pautado numa narrativa única glorificando a nação e os "heróis nacionais". Uma outra parte, imbuída pelas primeiras experiências com o ensino por temas e com a proposta dos eixos-temáticos no currículo de História paulista, resolveu optar por trabalhar com a história temática. Para os que escolheram essa possibilidade, deu início uma discussão ainda muito atual sobre questões relacionadas ao tempo histórico, re- 
vendo concepções de "linearidade" e "progressividade", noções de "decadência", "evolução" e "progresso" (Cf. Cordeiro, 1994).

Para Nadai, seria diante dessas críticas e questionamentos que estaria o ponto "fulcral" desse projeto de se refletir sobre a história ensinada no $1^{\circ}$ e $2^{\circ}$ graus, pois "diante das críticas ao caráter da história universal e da descrença na existência de uma história científica global, os professores não se cansam de indagar: que conteúdo deve ser selecionado? Deve-se partir da Grécia? Devese dar Roma? Deve-se ensinar Antigüidade Oriental? E a Idade Média? Deve-se estudar a América Anglo-Saxônica? Deve-se partir de qualquer problematização ou se deve garantir a formação da idéia de processo, de evolução, de movimento? Ou são fragmentação, as descontinuidades, as diferenças que interessam? É possível garantir-se uma história totalizante?" (Nadai, 1986, p. 113).

Muitas dessas questões encontraram eco no momento da construção e discussão das propostas curriculares de História nos Estados e municípios brasileiros envolvidos com a Reforma Curricular a partir de 1984.

\section{O PROFESSOR E A HISTÓRIA PRESCRITA NAS PROPOSTAS CURRICULARES}

A produção sobre a História a ser ensinada no ensino de $1^{\circ}$ e $2^{\circ}$ graus, apresentada pelos currículos oficiais que estão circulando no meio educacional a partir dos anos 1980 no Brasil, constitui-se como um conjunto heterogêneo, marcando um período peculiar da história da disciplina. Muitas das propostas elaboradas nos últimos quinze anos não se limitaram apenas em refazer metodologias e técnicas de ensino ou a introduzir pontualmente alguns conteúdos. Vivemos um momento dentro da história da disciplina em que os conteúdos e metodologias estão sendo reformulados de forma conjunta.

Uma leitura das propostas, num primeiro momento, pode deixar um sensação de ambivalências e contradições quanto à dimensão de tais transformações nos paradigmas da disciplina, porém, acreditamos que esta é uma condição inevitável levando-se em consideração que as intenções do poder instituído (ministérios e secretárias de educação) as das escolas não são precisamente coincidentes. Devemos ter em mente que há diferenças, clivagens e conflitos entre o "currículo pré-ativo" (prática idealizada), normativo e escrito pelo poder educacional institucional instituído e o currículo como prática em sala de aula ou "currículo interativo":

"o que está prescrito não é necessariamente o que é apreendido, e o que se planeja não é necessariamente o que acontece (...) devemos procurar estudar a construção social do currículo tanto em nível de prescrição como em nível de interação" (Goodson, 1999, p. 78).

Nessa perspectiva e nos limites de nossa abordagem, a questão central dessa parte do estudo concentra-se na análise sobre o grau de ruptura e continuidade dessas propostas em relação aos currículos de História anteriores, em termos metodológicos e de conteúdos, e suas articulações possíveis com o currículo "real", vivido por professores e alunos no espaço da sala de aula.

Após o fim do regime autoritário imposto pelos governos militares entre 1964 e 1985 e com necessidade urgente de formação de um Estado constitucional democrático, houve a abertura de espaços para a proposição e debate de reformulações nos currículos educacionais herdados da ditadura, numa tentativa de superálos, dando ensejo ao processo de demo- 
cratização das instituições públicas brasileiras.

No processo de democratização dos anos 1980, como foi observado, os conhecimentos escolares tanto teóricos quanto metodológicos passaram a ser questionados e redefinidos por reformas curriculares de governos e secretarias de educação dos Estados e municípios brasileiros. Simultaneamente, as mudanças do perfil da clientela composta por diversos grupos sociais que estavam vivendo um profundo processo de migração para áreas urbanas (como os principais centros urbanos do país - São Paulo e Rio de Janeiro), entre regiões (do Nordeste para o Sudeste e Sul), e entre Estados, com acentuada diferenciação econômica, social e cultural, também impuseram transformações no sistema educacional até então vigente.

A situação em que se encontravam as escolas brasileiras era muito complexa em relação à nova realidade sócio-econômica vivida pelo país desde as reformas políticas e econômicas feitas pelos militares.

$\mathrm{Na}$ área educacional, por exemplo, a ampliação do período de freqüência obrigatória para oitos anos, com a finalidade de deselitizar o ensino no país - trazidas pela Reforma Educacional de 1971 - havia ocorrido apenas na legislação, uma vez que as escolas públicas não dispunham de condições humanas e infra-estrutura para atender a este aumento da população de alunos.

A proposta de democratização do ensino público, amplamente defendida nas propagandas políticas institucionais dos governantes militares, que possuía por meta a identificação do sistema de ensino ao poder político estabelecido por estes, foi deficitária no campo prático, pois não houve nenhuma adequação e preparação das escolas e professores para esta mudança.

A estagnação crescente dos métodos e práticas de ensino quando comparados ao desenvolvimento tecnológico vivido com maior intensidade a partir dos anos 1980 foi um outro fator determinante na degradação do ensino. As novas gerações de alunos presentes nos bancos escolares, habituados às novas tecnologias de comunicação (rádio, televisão e internet), entravam em contato com uma escola pautada em métodos arcaicos e ultrapassados de ensino.

Adentrava pelos portões estreitos das escolas brasileiras uma nova realidade que não dava para ser mais ignorada pela sociedade, impondo necessárias mudanças, as quais ainda não foram realizadas.

Nesse contexto, diversos profissionais envolvidos com a área do ensino começaram a discutir e questionar de maneira intensa o sistema e a política educacional adotadas pelo Estado e a elaborar novas alternativas de ensino. No longo período de debates, os professores tiveram relevante papel na luta pela constituição de um saber escolar mais adequado às reais condições da população brasileira e na difícil tarefa de reduzir o poder e o monopólio dos chamados técnicos educacionais do Ministério da Educação oriundos da política centralizadora do Estado desde a ditadura Vargas (Abud, 1998, p. 107).

Durante esse momento de debates reforçou-se o diálogo e a aproximação entre os pesquisadores e/ou docentes universitários com os professores do ensino $1^{\circ}$ e $2^{\circ}$ graus.

O período posterior à volta da disciplina História ao currículo escolar do ensino de $1^{\circ}$ e $2^{\circ}$ grau tem sido marcado por pro- 
postas, polêmicas, confrontos e conflitos em relação a um novo currículo. Os atores sociais presentes nesses debates têm trazido nas suas falas e argumentações a necessidade de "aprofundar as questões relativas ao conhecimento que tradicionalmente vinha sendo ensinado e às novas tendências e avanços nos campos historiográfico e pedagógico" (Bittencourt, 1998, p. 13).

Essa aproximação entre a universidade e as escolas de $1^{\circ}$ e $2^{\circ}$ graus tem contribuído de forma significativa para o enriquecimento dessas discussões, contrariando, pois, o que havia sido marcante durante o período anterior, o amplo distanciamento entre os dois espaços.

As discussões em torno do ensino de História ganharam novo fôlego, ultrapassando as fronteiras dos espaços acadêmicos e escolares, com a Reforma Curricular para ensino de $1^{\circ}$ e $2^{\circ}$ graus realizada em todos os Estados brasileiros entre 1985 e 1995, Tal reforma veio com o objetivo de concretizar a readequação dos programas curriculares e suas metodologias para o ensino básico de oito anos.

Para Elza Nadai, as propostas curriculares elaboradas durante esse período, na sua totalidade, apresentavam-se de maneira

"variada, complexa e diferenciada quanto ao conteúdo, método ou estratégias de ensino. Algumas se caracterizam por sua natureza inovadora e progressista, outras pelo tom repetitivo e conservador. Todas, enfim, anseiam por superar a ficção da escolaridade obrigatória de oito anos" (1993, p. 158).

Essas propostas, como foi observado, também passaram a sofrer as influências do debate das tendências historiográficas emergentes a partir do final dos anos 1970. Os pesquisadores e professores de
História voltaram seus olhares para o estudo de novos problemas, novos objetos e novas abordagens, influenciados por questões ligadas à história social, cultural e do cotidiano, apresentando maneiras possíveis de rever o formalismo de abordagens históricas sustentadas nos fatos políticos e administrativos dos Estados ou nas análises estritamente economicistas (Cf. Le Goff ; Nora, 1979 ).

Influenciada por essas novas tendências da historiografia, a apresentação do processo histórico dentro de um eixo espaçotemporal europocêntrico, a partir de um processo evolutivo, seqüencial e homogêneo, foi criticado como produto pronto, acabado e redutor da capacidade do aluno se sentir na condição de sujeito comum parte integrante da história, e restritivo ao discernimento da diferença entre o conhecimento histórico produzido por acadêmicos e as ações dos seres humanos realizados no passado (Cruz, In: Nikitiuk, 1999, p. 67).

Paralelamente às análises historiográficas, surgiram novas pesquisas no âmbito das ciências pedagógicas, especialmente nq campo da psicologia social e cognitiva Difundiram-se estudos no Brasil sobre o processo de ensino-aprendizagem nos quais os alunos eram considerados como participantes ativos do processo de construção do conhecimento. Uma perspectiva que, para o ensino de História, representou a valorização das atitudes ativas do sujeito como "construtor" de sua história, em consonância com a visão de alguns

\footnotetext{
${ }^{8}$ Entre os estudos podemos citar as obras de Jean Piaget, Vygotsky, Luria e Leontiev. Esses autores da área da Psicologia tiveram muita influência na construção dos programas curriculares para a educação infantojuvenil no Brasil ao longo anos 1970, 1980 e 1990. Suas obras, por exemplo, foram referências básicas para a elaboração dos Parâmetros Curriculares Nacionais do Ensino Fundamental, do Ministério da Educação, nos anos 1990.
} 
educadores sobre as propostas pedagógicas construtivistas. Segundo Marilia Beatriz Cruz,

"uma nova concepção de ensino fundamentada principalmente nas teorias de Piaget $e$ Vygotsky, a concepção construtivista fornece subsídios para a superação das aulas expositivas como metodologia exclusiva, apontando caminhos para um ensino que estimule o desenvolvimento cognitivo dos alunos em direção a níveis qualitativamente superiores. A contribuição de Vygotsky, no que se refere à aprendizagem dos conceitos científicos e sua relação com os chamados conceitos espontâneos, já se constitui numa referência para a renovação do ensino de História. Interpretar o ensino de História como fornecedor de conceitos que facilitam a compreensão do mundo e que contribuem para construção de estruturas complexas pode ser considerado uma verdadeira revolução paradigmática, pois cria um novo modelo de ensino no qual já não cabem os nomes e datas para serem decorados, nem fatos fragmentados que em nada contribuem para a compreensão dos complexos problemas da vida do homem em sociedade" (Nikitiuk, 1999, p. 75).

Influenciados por essas novas concepções pedagógicas, os currículos foram ampliados com conteúdos de História a partir das escolas de educação infantil e nos primeiros anos do ensino de $1^{\circ}$ grau. Os conteúdos passaram a ser avaliados quanto às necessidades de atender um público ligado a um "presenteísmo" intenso, voltado para idéias de transformações constantes do novo cotidiano tecnológico.

Nesse momento, introduziu-se em algumas propostas curriculares a preocupação de fazer os professores desenvolverem com os alunos procedimentos básicos de pesquisa histórica na sala de aula e atitudes intelectuais de desmistificação de ideologias, das imagens de "heróis nacio- nais", da sociedade de consumo e dos meios de comunicação (Cf. Miceli, 1997). Em linhas gerais, segundo Maria Stephanou, o conhecimento presente nos currículos de História produzidos até os anos 1980 no Brasil pode ser caracterizado por deter-se sobre fatos passados, valorizando a ação de personagens especiais (heróis nacionais), cujas intenções, objetivos e propósitos são propulsores dos acontecimentos, destacados nos cenários das diferentes épocas; ênfase aos acontecimentos oficiais; apresentação dos fatos através de sucessões cronológicas, dispostos linearmente, convergindo para uma visão de evolução e de relações de causa-efeito; periodização assentada no modelo quadripartite francês (Idade Antiga, Média, Moderna e Contemporânea), ou ainda comunidade primitiva, escravismo, feudalismo, capitalismo/socialismo, de maneira que só parte da história do mundo ocidental que se insere nessa seqüência; inexistência de pontos programáticos referentes à África e sociedades orientais; a presença de uma visão dual e etnocêntrica das diferentes sociedades humanas (civilizados x primitivos, evoluídos $\mathrm{x}$ atrasados); ênfase no estudo do mundo ocidental, da vida de protagonistas masculinos, brancos, assim como de atributos masculinos (androcentrismo presente em valores como "bravura", "conquista", "desbravamento", "belicosidade"), alimentando igualmente o etnocentrismo, o europocentrismo, a xenofobia, o racismo e mal disfarçados preconceitos nacionalistas e genocídios; tendência a uma história assexuada, em que crianças, velhos, mulheres raras vezes são narrados, descritos ou sequer citados, prevalecendo uma representação do passado que negligencia o tratamento de grupos minoritários (no sentido de representatividade política); a humanidade, há milhares de anos, caminha numa rota linear, sem altos, embora com alguns desvios, em direção ao mun- 
do de hoje, que é representado como o máximo de progresso e desenvolvimento humano (Stephanou, 1998, p. 21-23).

Todo essa releitura em relação aos currículos anteriores conduziu a uma reavaliação da história ensinada pelas múltiplas possibilidades de abordagens historiográficas.

Essa diversidade de abordagens historiográficas e teórico-metodológicas foi constatada por Circe Bittencourt nas propostas curriculares de História produzidas entre 1985 e 1995 em todos os Estados brasileiros. Esse estudo das propostas curriculares de História elaborada pela autora serviu de referência para a elaboração de um relatório em 1996 com fins à formulação dos Parâmetros Curriculares Nacionais para o Ensino Fundamental. (Cf. Bittencourt, 1998).

Para a referida autora, as propostas caracterizaram-se como um conjunto muito heterogêneo de textos, com acentuadas diferenças na forma como foram construídas e apresentadas aos professores, no elenco dos conteúdos selecionados e nas metodologias de ensino sugeridas.

$\mathrm{Na}$ maioria das propostas, segundo $\mathrm{Bi}$ ttencourt, a apresentação formal demonstrou a superação do modelo tecnicista dos anos 1970, por intermédio da qual o currículo era seccionado em zonas estanques, elencados em quadros contendo os objetivos, os conteúdos e as atividades didáticas. Havia uma forte tendência de realizar uma delimitação da área do conhecimento "específica" da disciplina, fazendo referência das fundamentações pedagógicas e historiográficas (Bittencourt, 1998, p. 15).

Algumas delas traziam no seu texto o percurso ("democrático") de discussões com os professores de $1^{\circ}, 2^{\circ}$ e $3^{\circ}$ graus, buscando esclarecer os vários sujeitos produtores do referido texto. Tal atitude procurava considerar os possíveis liames e articulações entre o corpo burocrático de técnicos com a assessoria das universidades, como um resultado oriundo de debates com professores.

Esse percurso democrático de discussões curriculares nem sempre foi muito tranqüilo. Em São Paulo, por exemplo, durante os primeiros instantes de volta à democracia no governo estadual - gestão Franco Montoro (1983-1987) -, houve a iniciativa da Secretaria Estadual da Educação, através da Coordenadoria de Estudos e Normas Pedagógicas (CENP), de se construir uma proposta curricular para o ensino de $1^{\circ}$ e $2^{\circ}$ graus que fosse elaborada e discutida pelos próprios professores da rede oficial de ensino, em conjunto com os professores universitários (Cf. Martins, 1996). Entretanto, devido a conflitos e polêmicas, algumas delas, fruto de discussões e disputas acadêmicas e políticas tornadas públicas pela intervenção da imprensa, outras dentro da própria CENP e desta com os professores de História convidados a discutir as propostas, tornaram inviável a continuidade do projeto, sendo este interrompido em 1988 pela coordenadora, professora Teresa Roserley Neaubauer da Silva, durante a gestão Orestes Quércia (1987-1991) (Cf. Ricci, 1992; De Rossi, 1994).

No caso da área de História, as primeiras versões da proposta (três versões) foram produzidas e a equipe que as elaborou foram criticadas e acusadas, tanto por membros da academia quanto pelos órgãos de imprensa, que trouxeram os debates de forma sensacionalista ao conhecimento do público, com os rótulos de "esquerda radical", "marxista", "deturpadores da História "oficial"”, "populista", "irracionalista", entre outras adjetivações 
pejorativas. Tais análises presentes na imprensa contribuíram para a instituição de um universo vocabular para a rotulação da proposta da CENP e, também, para a inviabilização daquela iniciativa. $\mathrm{O}$ projeto da proposta de História foi retomado a partir de 1990 pela CENP, mas nesse momento sob a responsabilidade de uma equipe composta apenas por professores universitários (Cf. Cordeiro, 1994).

A experiência paulista remete-nos à afirmação de Ivor Goodson de que a elaboração do currículo pode ser considerada um processo pelo qual se inventa uma tradição. Mas, segundo o autor,

"como acontece com toda tradição, não é algo pronto de uma vez por todas; é, antes, algo a ser defendido, onde, com o tempo, as mistificações tendem a se construir e reconstruir sempre de novo. Obviamente, se os especialistas em currículo ignoram completamente a história e a construção social do currículo, mais fáceis se tornam esta mistificação e a reprodução de currículo "tradicional", tanto na forma como no conteúdo" (1999, p. 78).

Nas propostas analisadas há variação em diferentes aspectos das formulações dos conteúdos disciplinares. Os Estudos Sociais, num número significativo de propostas, permanece como disciplina nas séries iniciais do ensino de $1^{\mathrm{o}}$ grau $\left(1^{\mathrm{a}}\right.$ e $4^{\mathrm{a}}$ séries), embora não exista homogeneidade de concepções sobre tal área de conhecimento. Para as séries seguintes, a História e a Geografia aparecem como disciplinas autônomas, mas com uma enorme diversidade quanto ao tempo e espaço pelos quais devem começar os estudos históricos: Brasil e seus povos nativos ou Europa e Mediterrâneo ou pelo Brasil com a chegada dos europeus ou então pela préHistória.
Quanto à estrutura dos conteúdos, os modos de produção ordenam um número significativo das propostas entre $5^{\mathrm{a}}$ e $8^{\mathrm{a}}$ séries. A História do Brasil continua sendo analisada através dos três grandes eixos políticos (Colônia, Império e República), buscando articulá-los aos ciclos econômicos (pau-brasil, cana-de-acúcar, mineração, café, industrialização). As transformações mais emblemáticas aparecem com as propostas que ordenam o conhecimento histórico por temas ou eixos temáticos (Bittencourt, 1998, p. 1718). A proposta curricular paulista, por exemplo, apresenta a estrutura de seus conteúdos por intermédio de eixos temáticos ("A criança constrói sua história" Ciclo Básico, "A construção do espaço social: movimentos de população" - $3^{\mathrm{a}} \mathrm{e}$ $4^{\mathrm{a}}$ séries, "O construir das relações sociais: Trabalho" $-5^{\mathrm{a}}$ e $6^{\mathrm{a}}$ séries, "O construir da História: cidadania e participação" - $7^{\mathrm{a}}$ e $8^{\mathrm{a}}$ séries). Os autores da referida proposta fundamentam tal opção na perspectiva de que qualquer tema ou objeto permite apreender a totalidade do social, pois a totalidade não significa visão global (típica das análises por períodos), mas um certo tipo de relação do todo com as partes (Cf. São Paulo, 1992).

As propostas curriculares que introduzem os eixos temáticos, como a de São Paulo, segundo Bittencourt,

"embora pequem pela imprecisão em discernir eixos temáticos escolares de história temática tal qual tem sido realizada pela pesquisa historiográfica, justificam a opção pela constatação da impossibilidade de se "estudar toda a história da humanidade" e como meio de superar a noção de tempo evolutivo. Tais propostas, em número minoritário mas que servem de referência para outras incursões, apontam, ainda que de forma precária, para duas questões básicas: o que são conteúdos programáticos escolares e a possibilidade de uma maior participação dos profes- 
sores na seleção de conteúdos significativos para cada realidade escolar" (1998, p. 16).

Em suma, esse tipo de proposta, assumia um caráter inovador ao propor uma flexibilização curricular para a montagem e organização de conteúdos para a disciplina.

Quanto aos objetivos, a maioria das propostas curriculares tem como princípio contribuir para a formação de um "cidadão crítico". Elas almejam formar um aluno capaz de apresentar uma postura crítica em relação à sociedade em que vive. Nas introduções dos textos oficiais, essa preocupação está reiterada, insistindo que o ensino de História, ao estudar as sociedades passadas, tem como meta fazer o aluno compreender o tempo presente e perceber-se como ator social capaz de transformar a realidade, contribuindo para a construção de uma sociedade democrática (Idem, p. 19).

Contudo, se formos usar como referência o que tem sido ensinado sobre as sociedades passadas, não teremos "boas lições" de cidadania e de democracia para que as crianças possam se espelhar, pois como disse Fernand Braudel,

"Outra idéia que devemos abandonar: o ensino de História, ao que afirmam, deveria ter por finalidade a formação do cidadão, de um cidadão ideal, ademais. Mas a História, tal como está, como deve estar uma ciência incerta como todas que laboram no domínio social, se mantém fora da moral religiosa. Quando eficaz, a História forma um certo modo de ver, de julgar, uma certa maneira de ser, toda intelectual"' (1955, p.4).

Usar de uma história "moral", que olhe para acontecimentos ditos negativos das sociedades passadas como exemplos de conduta que as crianças não devam seguir, também não resolve o problema.
Como afirmou Eric Hobsbawm, talvez o problema do século XX foi que ele ensinou o ser humano a apenas julgar, e não compreender, pois compreender esteve sempre associado a perdoar ou aceitar (1999, p. 15).

Mais do que "cidadãos críticos", precisamos formar "cidadãos leitores", sujeitos capazes de realizar uma leitura interpretativa e compreensiva da História ou da "realidade". Precisamos de cidadãos críticos, mas que sintam necessidade e vontade de adquirir conhecimento. Talvez o prazer em aprender, em adquirir cultura, devesse ser desenvolvido com maior intensidade. Um ensino de História pautado apenas nas questões imediatas do cotidiano dos alunos daria a impressão de que o passado só faria sentido na medida em que se relacionasse diretamente com o local vivenciado pelo aluno.

Além disso, se analisarmos a história da disciplina desde sua constituição no século XIX e, principalmente, depois da Segunda Guerra Mundial, veremos que esse discurso de "formação do pensamento crítico", a formação de "posturas críticas" ou ainda "estudar o passado para compreender e transformar o presente" ( e planejar o futuro), não é tão inovador quando os autores das propostas curriculares dos anos 1980 e 1990 proclamam.

A inovação que aparece nesse discurso, para Bittencourt, estaria na ênfase dada ao papel da história ensinada para a compreensão do "sentir-se sujeito histórico" e em sua contribuição para a "formação de um cidadão crítico"(Bittencourt, 1998, p.19).

Apesar de concordamos, em parte, com esses aspectos, apresentamos algumas questões: por que caberia exclusivamente ao ensino de História a formação de uma cidadania crítica? Não seria esse uma 
meta da educação como um todo? E mais ainda, que tipo de cidadão crítico pretende-se se formar? Ao invés de pensarmos numa cidadania universal, não poderíamos falar em cidadania plural?

Na maioria das propostas, segundo a autora, a explicitação do conceito de cidadania é restringida à cidadania política, à formação do eleitor dentro das concepções democráticas universalizantes do modelo liberal. Será que tal definição consegue admitir posturas diversas?

"Nas séries iniciais, os conteúdos formulam o ensino das práticas políticas institucionais possíveis, indicando os cargos eletivos dos municípios e estados da Federação, e a divisão de poderes de Estado. Informam ainda os deveres cívicos dos Cidadãos, tais como a necessidade de pagamento de impostos, de prestação do serviço militar e têm sido introduzidos estudos sobre as leis de trânsito, surgindo, assim as idéias do Cidadãomotorista e do cidadão-pedestre e ainda da preservação do meio ambiente nas séries iniciais" (Idem, p. 22).

A idéia de cidadania social é pouco desenvolvida e caracterizada em tais propostas, mesmo quando as fundamentações teóricas são baseadas na constituição e na transposição de uma história social e cultural para o ensino. Aqui, talvez, podemos perceber uma tentativa de trazer o velho discurso em novas roupagens. Usar terminologias e "jargões de área" que mudam apenas na aparência e o conteúdo continua o mesmo (Cordeiro, 1994, p. 59).

Segundo Bittencourt, apenas uma proposta curricular apresenta preocupações em situar a cidadania como objeto de estudo, compreendendo-a como uma conquista historicamente determinada e não uma espécie de concessão divina ou de alguma entidade superior.
"A idéia de cidadania social que abarca os conceitos de igualdade, de justiça, de diferenças, de lutas e de conquistas, de compromissos e de rupturas tem sido apenas esboçada em algumas poucas propostas. E, mais ainda, existe uma dificuldade em explicitar a relação entre cidadania social e política, entre cidadania e trabalho" (1998, p. 22).

Outro aspecto a ser analisado é que há uma certa convergência das propostas na crítica às noções de tempo impostas pelos currículos de História anteriores, oriundos dos paradigmas positivistas e que precisam ser superados. De maneira quase unânime,

"as formulações de novas propostas curriculares são justificadas ao se apresentarem como meio de superar um ensino de História que se fundamenta na construção de um tempo histórico homogêneo, determinado pelo europocentrismo e sua lógica de periodização baseada no sujeito histórico Estadonação. E, nessa perspectiva, propõem-se a trabalhar com as diferentes temporalidades $e$ diferentes sujeitos" (Idem, p. 23).

Da análise de Bittencourt sobre as atuais propostas, quando comparadas com as anteriores aos anos 1980, podemos notar que a maioria apresenta críticas quanto aos conteúdos de História voltados ou para uma história nacional subordinada à ótica da matriz européia ou para uma história centrada nos modos de produção, com base no estruturalismo que imobiliza as ações dos indivíduos em sociedades, principalmente as periferias do mundo desenvolvido (Idem).

Dessa maneira, para autora, as justificativas das propostas apontariam para a alteração e superação da concepção de tempo evolutivo e progressista. Contudo, nessa perspectiva, foi possível perceber que a periodização das propostas, sejam as que mantêm um conteúdo "tradicional" ou 
baseados nos "modos de produção", sejam as que optaram por eixos-temáticos, é estabelecida e organizada pela ótica do capitalismo (Idem).

Apesar de um número significativo dessas propostas afirmar seu diálogo aberto com os novos rumos da historiografia, Bittencourt percebeu que ainda constituise um desafio para os autores dos novos currículos articular a produção científica que introduz o social e o cultural com o saber escolar a ser ministrados para os alunos do ensino de $1^{\circ}$ e $2^{\circ}$ graus.

Para a referida autora,

"Alguns conceitos básicos como os de classe social, trabalho e alienação poderiam ser melhor explicitados para a formulação de lutas e movimentos sociais, estendendo a concepção de ação política para a esfera das organizações da sociedade civil, dos sindicatos e de lutas de resistências diversas, conforme preconizam estudos do cotidiano, como os de E. P. Thompson, Agnes Heller, Maria Odila da Silva, Michel de Certeau, Henri Lefebvre, entre outros" (Idem, p. 25).

Acreditamos que o problema esteja no fato dos autores das propostas curriculares não entenderem que o conhecimento histórico escolar não pode ser entendido como mera e simples transposição de um conhecimento maior, proveniente da historiografia e que é vulgarizado e simplificado pelo ensino. E, nesse sentido, é fundamental considerar o papel do professor - sujeito fundamental na transformação ou continuidade da história ensinada - na configuração de "currículo interativo", que acontece na sala de aula.

Se continuarmos a pensar dessa maneira, assumiremos a máxima, tão criticada nos anos 1980 e 1990, que a academia produz o conhecimento e a escola reproduz, ou pior, vulgariza (Costa, 1957, p. 117-20).
Em linhas gerais, das propostas curriculares de História produzidas ao longo dos anos 1980 e 1990 poucas conseguiram sair do campo da teoria para o prático. Muitas nem saíram das discussões das versões preliminares. Segundo Bittencourt,

"tornou-se evidente que poucas conseguiram alcançar, de forma coerente, os propósitos lançados iniciais estabelecidos e considerados para a disciplina" (Barretto, 1998, p. 158).

Todavia, podemos evidenciar, de maneira geral, de acordo com sua análise, que foi introduzido um discurso pautado em parâmetros atualizados, apresentando pressupostos teóricos que manifestaram uma busca de transformações no ensino de História.

"A figura do professor adquire papel central e são esboçados novos conceitos de aprendizagem, mesmo que nem sempre muito coerentes, ao situarem o aluno como sujeito de conhecimento e portador de algum tipo de saber. Essas intenções, no entanto, se concretizam de forma ainda limitada nos conteúdos e nos métodos de ensino" (Idem).

O principal problema dessas propostas curriculares (e mesmo dos Parâmetros Curriculares Nacionais) está no fato delas esquecerem de levar em consideração na sua elaboração aspectos significativos da formação do professor de História e suas condições de ensino. Segundo Bittencourt, essas propostas são falhas porque trabalham com uma concepção diferente de professor: intelectual-pesquisador (Idem, 157-58).

Entretanto, segundo a autora, a falha dessas propostas não estaria na concepção de um professor diferente e, sim, na falta de uma menção “à forma como essa mudan- 
ça essencial e necessária do trabalho docente, será concretizada para a efetivação das propostas curriculares" (Idem).

Experiências vivenciadas por profissionais envolvidos com o debate sobre o ensino de História, no caso específico de Estado de São Paulo, aproximam-se das observações de Bittencourt, ao afirmarem que, quando apresentada e debatida a proposta curricular de História da CENP com os professores da rede estadual de ensino constatou-se que esta parecia ter "marginalizado" o professor, esquecendo de levar em consideração seu cotidiano apesar de valorizar o dia-a-dia dos alunos (Miceli, 1996, p. 284-86).

Ao analisar a questão do papel desempenhado pelos professores dentro da elaboração e aplicação dos novos currículos de História, Paulo Celso Miceli trouxe para o debate sobre a Reforma Curricular a necessidade de se dar atenção ao cotidiano destes profissionais. Para este autor, os professores, por falta de tempo ou condições, têm sido a cada dia menos estimulados e qualificados, o desânimo e o receio de ensinar é enorme, ficando assim a educação em posições trocadas e em caminhos opostos no país (Idem, 287).

O modelo de professor idealizado no interior das propostas curriculares, na leitura de Miceli, não corresponderia ao professor "real" que tem seu ofício diariamente transformado, por exemplo, na

"vergonha do subemprego, denunciado nas imensas filas dos 'bancos oficiais' nos dias de pagamento e na reduzida presença dos professores em filas outras que prometem o lazer, o prazer ou o acesso a formas de cultura que acabaram elitizadas, como o teatro e, até, o cinema" (Idem, p. 300).
A partir dos anos 1980, em todos os debates nos quais se colocam questões relativas ao ensino, pesquisa histórica e reforma curricular, começaram a emergir com maior intensidade debates dentro e fora da academia sobre a formação e prática do professor de História (Schmidt, In: Bittencourt, 1998, p. 54).

As recentes reformulações ocasionadas pela Lei de Diretrizes e Bases da Educação Nacional, de dezembro de 1996, são identificadas como significativas para a ampliação dos debates sobre a questão da reforma do sistema educacional nacional. No caso específico da disciplina História, os debates estão centrados nas novas proposições apresentadas pelos Parâmetros Curriculares Nacionais (PCNs) para o ensino fundamental e médio e nas determinações da referida Lei para os cursos de graduação e pós-graduação, principalmente no que concerne à formação dos professores (Cf. Brasil, 1996).

\section{REFERÊNCIAS BIBLIOGRÁFICAS}

BARRETTO, E. S. de S. (Org.). Os currículos de ensino fundamental para as escolas brasileiras. Campinas, SP: Autores Associados/Fundação Carlos Chagas, 1998.

BITTENCOURT, C. M. F (Org.). O saber histórico na sala de aula. 2. ed. São Paulo: Contexto, 1998.

BRASIL. Lei n. 0.394 - 20 dez. 1996. Lei de Diretrizes e Bases da Educação Nacional. Brasília, DF: MEC, 1996.

Parâmetros Curriculares Nacionais. Brasília, DF, MEC/SEF, 1997.

BRAUDEL, F. Conferência: pedagogia da história. Revista Brasileira de História, São Paulo, v. 11, n. 23, ano VI, p.3-21, jul./set. 1955. 
BURKE, P. A escola dos Annales : (19391989). São Paulo: UNESP, 1990.

A escrita da história: novas perspectivas. São Paulo: UNESP, 1992.

CABRINI, C. et al. Ensino de história: revisão urgente. São Paulo: Brasiliense, 1986.

CARDOSO, C. F. ; R. Vainfas (Org.). Domínios da história. 5.ed. Rio de Janeiro: Campus, 1997.

CHARTIER, R. A história cultural: entre representações e práticas. Lisboa: DIFEL, 1990.

CORDEIRO, J. F. P. A história no centro do debate: da crítica ao ensino ao ensino crítico. São Paulo, 1994. Dissertação (Mestrado em Educação) - Faculdade de Educação - UNICAMP.

COSTA, E. V. Os objetivos do ensino de História no curso secundário. Revista Brasileira de História, São Paulo, v. 14, n. 29, p.117-20, janeiro/março de 1957.

DE CERTEAU, M. A Escrita da história. Rio de Janeiro: Forense-Universitária, 1982.

A invenção do cotidiano. Petrópolis, RJ: Vozes, 1994.

DE ROSSI, V. L. S. Refazendo a escola pública? tropeços e conquistas. Campinas, SP, 1994. Dissertação (Mestrado em Educação) - Faculdade de Educação, UNICAMP.

FOUCAULT, M. Microfísica do poder. Rio de Janeiro: Graal, 1979.

FREIRE, P. Pedagogia do oprimido. Rio de Janeiro: Paz e Terra, 1975.

FREITAS, M. C. (Org.). A Historiografia brasileira em perspectiva. São Paulo: Contexto/USF, 1998.
GOODSON, I. F. Currículo: história e teoria. 3.ed. Petrópolis: RJ, Vozes, 1999.

HOBSBAWM, E. J. Era dos extremos: o breve século XX. 2.ed. São Paulo: Cia. das Letras, 1999.

HUNT, L. A. (Org.). A nova história cultural. São Paulo: Martins Fontes, 1992.

LAPA, J. R. do A. História e historiografia: Brasil pós 1964. Rio de Janeiro: Paz e Terra, 1985.

Historiografia brasileira contemporânea (a história em questão). Petrópolis, RJ: Vozes, 1981.

LE GOFF, J. et al. A Nova história. Lisboa: Edições 70, 1984.

LE GOFF, J. \& P. Nora (Org.). História: Novas abordagens, novos problemas, novos objetos. 2. ed. Rio de Janeiro: Francisco Alves, 1979 (3 volumes).

LENSKIJ, T. \& HELFER, N. E. (Org.). A memória e o ensino de História. Santa Cruz do Sul, RS: EDUNISC/ANPUH-RS, 2000 .

MARTINS, M. do C. A construção da proposta Curricular da CENP no período de 1986 a 1992: confrontos e conflitos. Campinas, SP, 1996. Dissertação (Mestrado em Educação) - FE - UNICAMP.

MICELI, P. C. História, histórias: o jogo dos jogos. Campinas, SP: IFCH - UNICAMP, 1996.

NADAI, E. A escola pública contemporânea: os currículos oficiais de História e o ensino temático. Revista Brasileira de História, São Paulo, v. 06, n. 11, p.99-116, set. 1985/fev. 1986.

O ensino de História no Brasil: trajetória e perspectiva. Revista Brasileira de História, São Paulo, v. 13, n. 25/26, p.143-62, set. 1992/ ago. 1993. 
NIKITIUK, S. L. (Org.). Repensando o ensino de História. $2^{\mathrm{a}}$ ed. São Paulo: Cortez, 1999.

PINSKY, J. (Org.). O ensino de história e a criação do fato. 6.ed. São Paulo: Contexto, 1994.

RAGO, L. M. ; GIMENES, R. A. de O. (Org.). Narrar o passado, repensar a história. Campinas, SP: UNICAMP - IFCH, 2000.

RAGO, L. M. A Nova Historiografia Brasileira. [S.l.p.]. (Mimeogr.).

RICCI, C. S. Da intenção ao gesto - quem é quem no ensino de História em São Paulo. São Paulo, 1992. Dissertação (Mestrado em História) - PUC-SP.

SÃO PAUlO (Estado). SEE/CENP. Proposta curricular para o ensino de História $-1^{\circ}$ grau. São Paulo, 1992.

SILVA, M. A. (Org.). Repensando a História. Rio de Janeiro: ANPUH/Ed. Marco Zero, 1984.

STEPHANOU, M. Currículos de História: Instaurando maneiras de ser, conhecer e interpretar. Revista Brasileira de História, São Paulo, v. 18, n. 36, p.15-38, 1998.

\section{Agradecimentos:}

Agradecemos aos professores Paulo $C$. Miceli (orientador), Pedro Paulo Funari e Célia Maria M. de Azevedo, pela leitura e sugestões apresentadas a este ensaio, assim como para a Monografia de Bacharelado do qual este faz parte. A responsabilidade pelas idéias, naturalmente, restringe-se ao autor.

RENILSON ROSA RIBEIRO

Bacharel e Mestrando em História Cultural do

IFCH/UNICAMP e-mail: rrenilson@yahoo.com 